\title{
Investigation of the properties of zinc oxide based heterostructures
}

\author{
A. R. Semenov ${ }^{\otimes 1}$, T. A. Kholomina ${ }^{1}$, V. G. Litvinov ${ }^{1}$, A. V. Ermachikhin ${ }^{1}$ \\ ${ }^{1}$ Ryazan State Radio Engineering University named after V. F. Utkin, 59/1 Gagarina Str., Ryazan 390005, Russia
}

\begin{abstract}
Authors
Andrey R. Semenov, ORCID: 0000-0003-2780-5661, e-mail: sem-a-sem@mail.ru

Tatiana A. Kholomina, ORCID: 0000-0003-3902-618X, e-mail: marta.tap@yandex.ru

Vladimir G. Litvinov, ORCID: 0000-0001-6122-8525, e-mail: vglit@yandex.ru

Alexander V. Ermachikhin, ORCID: 0000-0002-3808-9691, e-mail: al.erm@mail.ru

For citation: Semenov, A. R., Kholomina, T. A., Litvinov, V. G., Ermachikhin, A. V. (2021) Investigation of the properties of zinc oxide based heterostructures. Physics of Complex Systems, 2 (4), 172-179. https://www.doi.org/10.33910/2687153X-2021-2-4-172-179

Received 21 September 2021; reviewed 8 October 2021; accepted 8 October 2021.

Funding: The research was supported by the Ministry of Science and Higher Education of the Russian Federation as part of a state task (FSSN-2020-0003).

Copyright: ๔ A. R. Semenov, T. A. Kholomina, V. G. Litvinov, A. V. Ermachikhin (2021). Published by Herzen State Pedagogical University of Russia. Open access under CC BY-NC License 4.0.

Abstract. The paper presents the results of an experimental study of the electric properties of ZnO-based polycrystalline heterosructures. $\mathrm{C}$-V-characteristics of $\mathrm{In} / \mathrm{ZnO} / \mathrm{n}-\mathrm{Si} / \mathrm{Al}$ and $\mathrm{Au} / \mathrm{ZnO} / \mathrm{n}-\mathrm{Si} / \mathrm{Al}$ heterostructures were modeled. Influence of upper contacts material and annealing technology on structure characteristics was investigated. Surface states influence according to applied theoretical model was analyzed. Empirical dependence of the surface potential in silicon on the voltage applied on the structure was derived.
\end{abstract}

Keywords: surface states, heterostructures, $\mathrm{ZnO}, \mathrm{C}-\mathrm{V}$-characteristics, I-V-characteristics.

\section{Introduction}

In recent years, many scientific studies have been devoted to the study of the properties of zinc oxide. Zinc compounds are widely distributed in nature, therefore, zinc oxide is of interest as a straight-band semiconductor with a large $(3.36 \mathrm{eV})$ band gap. The unalloyed material has an electronic type of conductivity in combination with good optical properties and resistance to radiation (Pintilie, Pintilie 2001). $\mathrm{ZnO}$ is a promising material for the production of transparent conductors in solar cells, LEDs, laser diodes, and UV photodiodes. Due to the possibility of obtaining structures with high electronic mobility, the material can be used in high-speed UV radiation sensors (Kaidashev et al. 2003).

The purpose of this work is to study the phenomena of charge transfer in semiconductor heterostructures under the action of an electric field for the development of ideas about the features of physical phenomena in microcrystalline zinc oxide films.

\section{Samples and investigation methods}

In this work, we analyzed and compared the parameters of semiconductor heterostructures of two types: zinc oxide films grown on an $\mathrm{n}+$ silicon substrate with non-rectifying In contacts and rectifying Au contacts deposited on their surface (Fig. 1). The structures were annealed in argon and oxygen gases at a temperature of $600^{\circ} \mathrm{C}$. Annealing the samples of group 1 was carried out in an Ar environment, and for groups $2-4$ in an oxygen atmosphere. The indium contacts were in the form of a square with a side 

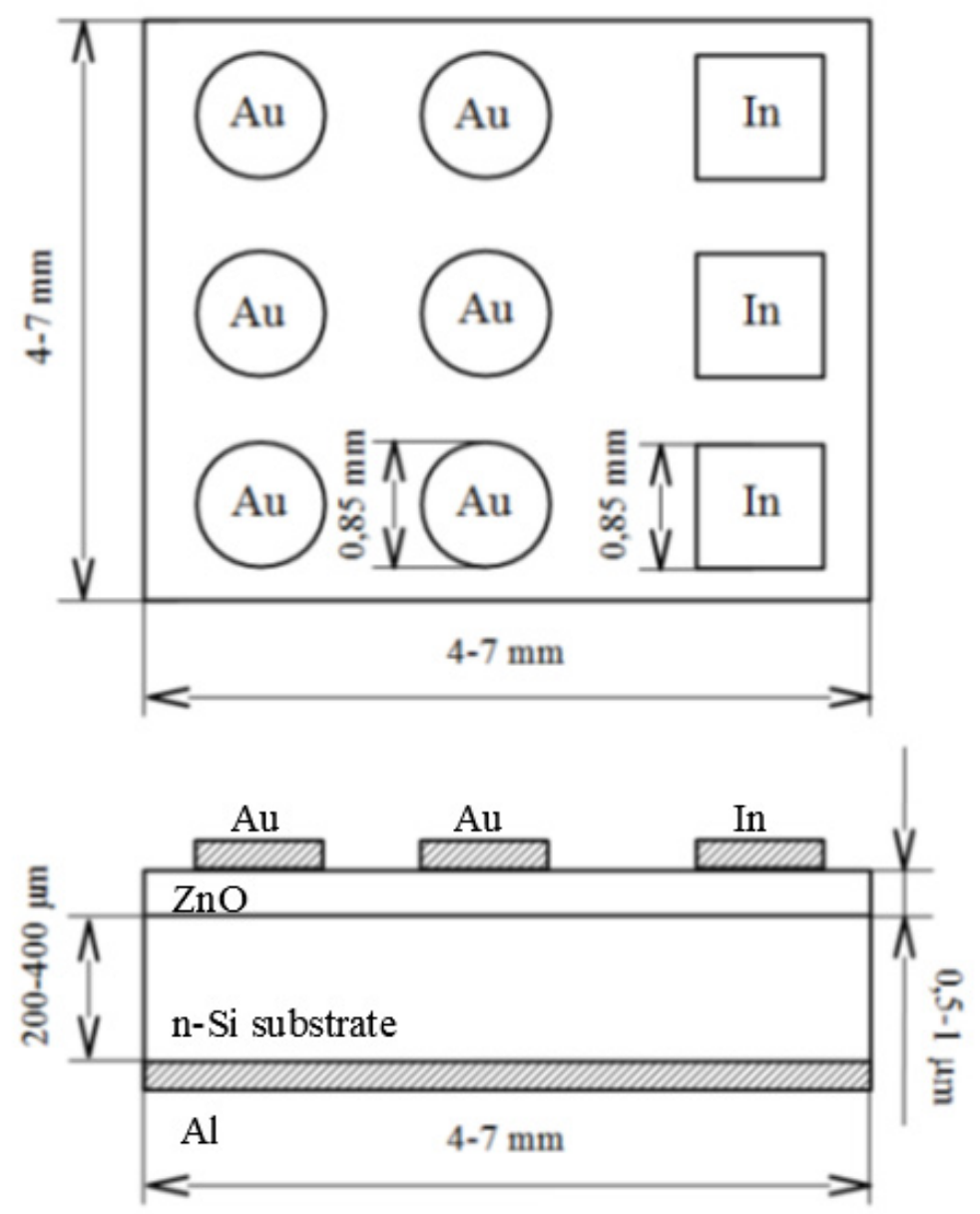

Fig. 1. Sample structure

of $0.85 \mathrm{~mm}$, and the gold contacts were in the form of a circle of the same diameter. Ohmic aluminum contacts are deposited on the silicon substrate on the reverse side of the plate.

The properties of the samples were investigated by the methods of current-voltage (I-V) and capacitancevoltage $(\mathrm{C}-\mathrm{V})$ characteristics. The I-V and C-V characteristics were measured using an Agilent E4980A RLC meter.

\section{Experimental results}

The I-V characteristics of the $\mathrm{Au} / \mathrm{ZnO}$ contacts were asymmetric, typical of diode structures. For the samples of group 1, an electrical breakdown was recorded at a reverse bias voltage of more than $4.7 \mathrm{~V}$, in connection with which the I-V characteristics of sample groups 1-4 were further measured in the range from -3.5 to $3.5 \mathrm{~V}$ (Fig. 2).

The samples of group 1 showed the most pronounced rectifying I-V characteristic with a threshold voltage of about 1.8 V. For the samples of groups 2 and 3, the forward threshold voltage was about $2.1 \mathrm{~V}$. At the same time, for the samples from group 4, the I-V characteristic in the test range was almost linear.

The I-V characteristics of the structures under study, obtained on ohmic In contacts, are shown in Fig. 3. The I-V characteristics were linear and symmetric. The resistivity of the $\mathrm{ZnO}$ layer was estimated from the linear part of the current-voltage characteristics, which turned out to be no less than $10^{5} \mathrm{Ohm} \cdot \mathrm{cm}$ for all the samples, which made it possible to consider $\mathrm{ZnO}$ as a dielectric (Litvinov et al. 2018). The resistances of thin layers of $\mathrm{ZnO}$ are calculated and are approximately equal to $0.97 \mathrm{MOhm}$ for group 1; $0.40 \mathrm{MOhm}$ for group 2; $1.43 \mathrm{MOhm}$ for group 3 and 1.19 MOhm for group 4.

Annealing the samples in an argon atmosphere (group 1) practically does not lead to a change in the oxygen content in $\mathrm{ZnO}$. It can be assumed that for the samples with a smaller thickness of group 3, the effect of the annealing atmosphere turned out to be more significant (Gromov et al. 2013). Annealing 


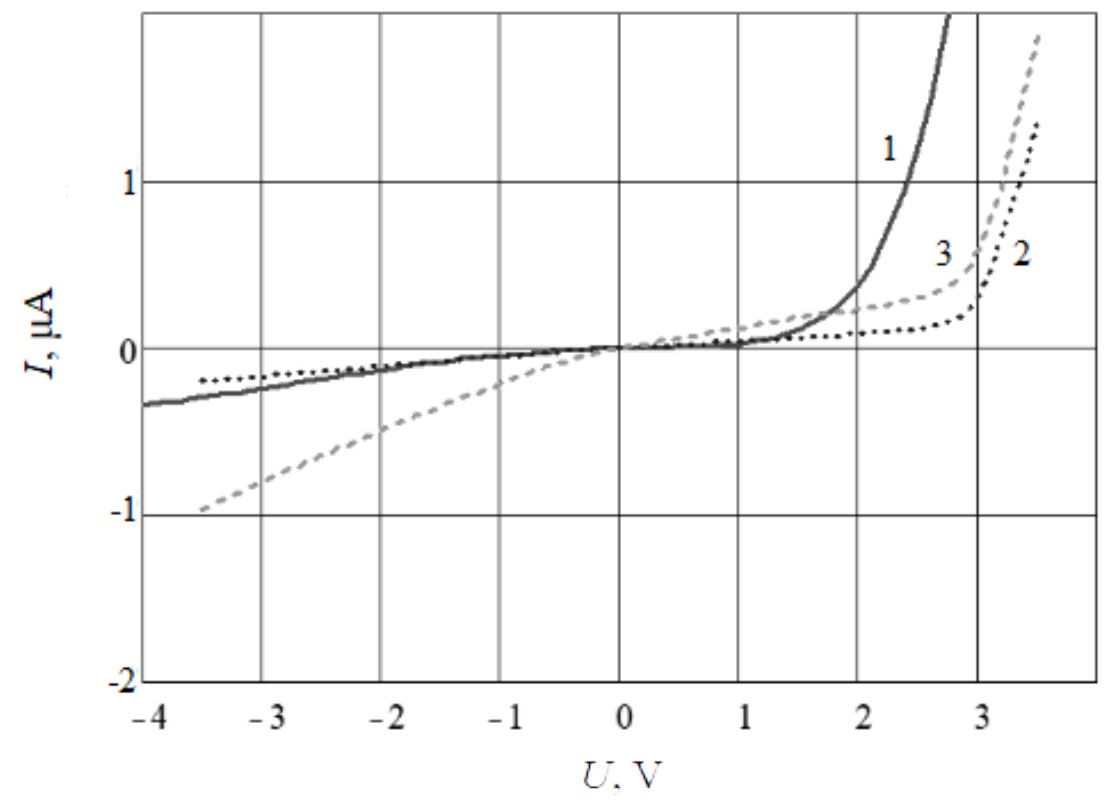

Fig. 2. I-V characteristics of barrier Au contacts for the samples of batches 1-3

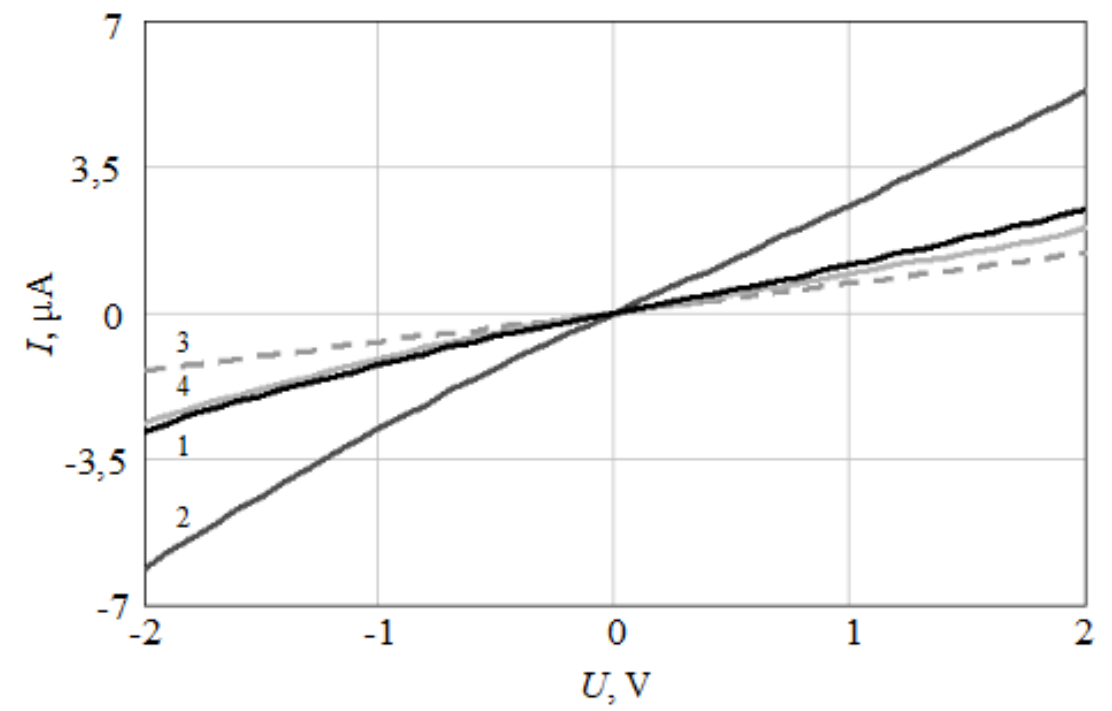

Fig. 3. I-V characteristics of $\mathrm{In} / \mathrm{ZnO} / \mathrm{n}-\mathrm{Si} / \mathrm{Al}$ contacts of the samples annealed in oxygen $(1,2,3)$ and argon $(4)$

in oxygen led to a decrease in the resistance of the structure and a weak nonlinearity of the I-V characteristic. Presumably, this difference is caused by the presence of hydrogen atoms in the interstices of the crystal lattice of $\mathrm{ZnO}$, which play the role of shallow donors (Ellmer et al. 2008).

Annealing is likely to result in the adsorption of oxygen atoms and the "healing" of oxygen defectsthe incorporation of oxygen atoms into the $\mathrm{ZnO}$ crystal lattice and their bonding with zinc atoms $\mathrm{Zn}+$ (Gromov et al. 2013). Zinc atoms $\mathrm{Zn}+$ are located in interstices or in the lattice sites, but are not associated with oxygen atoms. The resistance of the sample of group 4 is higher than the resistance of the sample of group 1, which allows us to conclude that the annealing was carried out in a humid oxygen environment. In oxygen, some amount could contain residual gases, the atoms of which are donors. Sample group 2 had the lowest resistance, which indicates a large number of impurity donor atoms of residual gases and hydrogen.

The analytical relations, in accordance with which the calculation of the values of the electrophysical parameters of thin ZnO films were made, are given in (Muller et al. 2003; Oreshkin 1977). 
The concentration of donors $\mathrm{N}_{\mathrm{d}}$ in highly doped $\mathrm{n}$-type silicon, according to the sample manufacturers, was about $10^{18} \mathrm{~cm}^{-3}$. Our calculations showed that the Fermi level in $\mathrm{ZnO}$ for all groups of samples turned out to be above the middle of the band gap, which corresponds to the n-type conductivity.

The experimental $\mathrm{C}-\mathrm{V}$ characteristics of the investigated heterostructures are, in general, similar to the characteristics of MIS structures. Small differences were observed in the region of enrichment of the $\mathrm{ZnO} / \mathrm{n}$-Si interface with charge carriers. Therefore, to analyze the $\mathrm{C}-\mathrm{V}$ characteristics of heterostructures with $\mathrm{ZnO}$ films, in this work, we applied the theoretical model of the MIS structure, since the highresistance layers of wide-gap zinc oxide act as a dielectric.

The approximation of the experimental $\mathrm{C}-\mathrm{V}$ characteristics was carried out in the areas of weak inversion, depletion and accumulation of low-frequency $\mathrm{C}-\mathrm{V}$ characteristics of the ideal MIS structure. The constructed model curves were the dependences of the capacitance on the surface potential $\psi_{s}$ or the potential on the depleted layer of the semiconductor substrate (Sze 1981).

The capacitance of the structure is presented as a series connection of the capacitance of the dielectric and the differential capacitance of the semiconductor:

$$
\begin{gathered}
C_{D}=-\frac{\varepsilon_{s} \varepsilon_{0}}{\sqrt{2} L_{D}} \frac{1-e^{\beta \psi_{s}+\left(p_{n_{0}} / n_{n_{0}}\right)\left(1+e^{-\beta \psi_{s}}\right)}}{F\left(\beta \psi_{s}, p_{n_{0}} / n_{n_{0}}\right)}, \\
C_{\text {Theory }}\left(\psi_{s}\right)=\left(\frac{1}{C_{E i}}+\frac{1}{C_{D}\left(\psi_{S}\right)}\right)^{-1} .
\end{gathered}
$$

where $C_{D}\left(\psi_{s}\right)$-effective differential capacitance of depleted semiconductor layer, $C_{E i}$-effective dielectric capacitance, $C_{\text {theory }}\left(\psi_{s}\right)$-effective theoretical capacitance of MOS structure, $\varepsilon_{s}$ - relative permittivity of semiconductor, $\varepsilon_{0}$-dielectric constant, $L_{D}$-electron Debye length, $\beta$-coefficient $\beta=q / k T, q$-elementary charge, $k$-Boltzmann constant, $T$-temperature, $n_{0}$ and $p_{0}$-equilibrium concentrations of electrons and holes respectively. The function $F\left(\psi_{s}\right)$ is defined as

$$
F\left(\psi_{S}\right)=\sqrt{\left(-\exp \left(\beta \psi_{S}\right)+\beta \psi_{S}+1\right)-\frac{n_{0}}{p_{0}}\left(\exp \left(-\beta \psi_{S}\right)+\beta \psi_{S}+1\right)} .
$$

Flat band capacity of the selected sample was found as the capacity at the surface potential $\psi_{s}=0$. In that case effective differential capacitance is defined as

$$
C_{D}(0)=\frac{\varepsilon_{S} \varepsilon_{0}}{L_{D}}
$$

Since zero surface potential on ideal MIS structure is equal to zero voltage on the investigated structure, then the value of the fixed charge is determined by the shift of the experimental dependence on the stress axis. Surface charge is generally a sum of several components (Sze 1981):

- the charge captured by surface traps;

- fixed oxide charge near the interface of semiconductor and dielectric;

- trapped oxide charge generated by $\mathrm{x}$-ray irradiation of structures or injection of hot electrons into the dielectric;

- the charge of mobile ions.

In the model we use, a fixed oxide charge $\mathrm{Q}_{f}$ is considered to be prevailing because other components of the surface charge can be neglected: the samples were not exposed to radiation, the charge captured by surface traps is considered as nonexistent when $\psi_{s}=0$ and under existing fabrication conditions the presence of mobile ions is unlikely.

Fixed charge in the real MIS structure was defined as (Sze 1981): 


$$
Q_{f}=C_{E i} \times\left(\varphi_{m s}-\Delta U_{F B}\right) .
$$

The next stage of the analysis was to determine the density of surface states at the $\mathrm{ZnO}$-Si interface. The calculation of the density of surface states was carried out by the high-frequency capacitive method based on the concepts described by Terman (Semenov et al. 2018). It was assumed that the change in the charge on the structure in the state of flat bands is the same for small changes in the voltage on the structure and the surface potential (Sze 1981).

The value of the derivative of the surface potential from the voltage $d \psi_{S} / d U$ is found as the ratio of the derivative of the experimental capacitance versus the voltage across the structure and the derivative of the calculated capacitance versus the surface potential of the semiconductor.

When connecting Au-substrate contacts, for example, the samples of group 2, the $\mathrm{d} \psi_{\mathrm{s}} / \mathrm{dU}$ value in the state of flat zones was 0.28 . The density of surface states $D_{i t}$ is determined by the formula (Sze 1981):

$$
D_{i t}=\frac{C_{E i}}{q}\left(\left(\frac{d \psi_{S}}{d U}\right)^{-1}-1\right)-\frac{C_{D}}{q} .
$$

In the first approximation, the derivative $\mathrm{d} \psi_{\mathrm{s}} / \mathrm{dU}$ was considered constant at all voltage values, therefore, $\psi_{\mathrm{S}}=0.28 \times \mathrm{U}$.

The CV characteristics were used to calculate the spectra of the density of surface states at the $\mathrm{ZnO} / \mathrm{n}$-Si interface, from which it follows that upon annealing zinc oxide films in argon, the effective density of states of $\mathrm{Au} / \mathrm{ZnO} / \mathrm{n}$-Si heterostructures is approximately an order of magnitude higher than upon annealing in oxygen $\left(3.5 \times 10^{12}\right.$ and $6 \times 10^{11} \mathrm{eV}^{-1} \mathrm{~cm}^{-2}$, respectively).

As a result of the analysis of the experimental data, the following values of the parameters of the samples were obtained, shown in Table 1.

Calculations showed that the obtained values of the concentration of charge carriers and the capacitance of the dielectric for different samples were of approximately the same order of magnitude, which agrees with the manufacturing conditions. The obtained values of the effective density of surface states are in the range characteristic of the silicon-dielectric interface.

The value of the relative permittivity, according to calculations, turned out to be below the table value $\left(\varepsilon_{\mathrm{i}}=9\right)$. It can be assumed that this is caused by the inhomogeneity of the surface of the $\mathrm{ZnO}$ films and requires additional study.

The theoretical and experimental C-V characteristics are shown in Figure 4.

\begin{tabular}{|c|c|c|c|c|}
\hline \multirow[t]{2}{*}{ Parameter } & \multicolumn{4}{|c|}{ Sample group } \\
\hline & 1 & 2 & 3 & 4 \\
\hline $\mathrm{ZnO}$ film thickness $\mathrm{d}, \mu \mathrm{m}$ & 0.71 & 0.84 & 0.62 & 1.2 \\
\hline Sample resistance $\mathrm{R}, \mathrm{MOhm}$ & 0.97 & 0.4 & 1.43 & 1.19 \\
\hline Sample resistivity $\rho, \mathrm{MOhm} \cdot \mathrm{cm}$ & 98.7 & 34 & 165.8 & 71.9 \\
\hline Concentration of free charge carriers (electrons) in $\mathrm{ZnO}, \mathrm{n}_{0} \times 10^{8}, \mathrm{~cm}^{-3}$ & 3.16 & 9.18 & 1.88 & 4.34 \\
\hline Effective density of states in the conduction band in silicon, $\mathrm{N}_{\mathrm{c}}, \mathrm{cm}^{-3}$ & \multicolumn{4}{|c|}{$3,5 \times 10^{18}$} \\
\hline $\begin{array}{l}\text { Position of the Fermi level relative to the bottom of the conduction } \\
\text { band } W_{f}-W_{c}, e V\end{array}$ & -0.6 & -0.57 & -0.61 & -0.59 \\
\hline Work function $\mathrm{q} \varphi_{\mathrm{s}}, \mathrm{eV}$ & 4.95 & 4.92 & 4.96 & 4.94 \\
\hline
\end{tabular}

Table 1. Parameters of the investigated heterostructures 


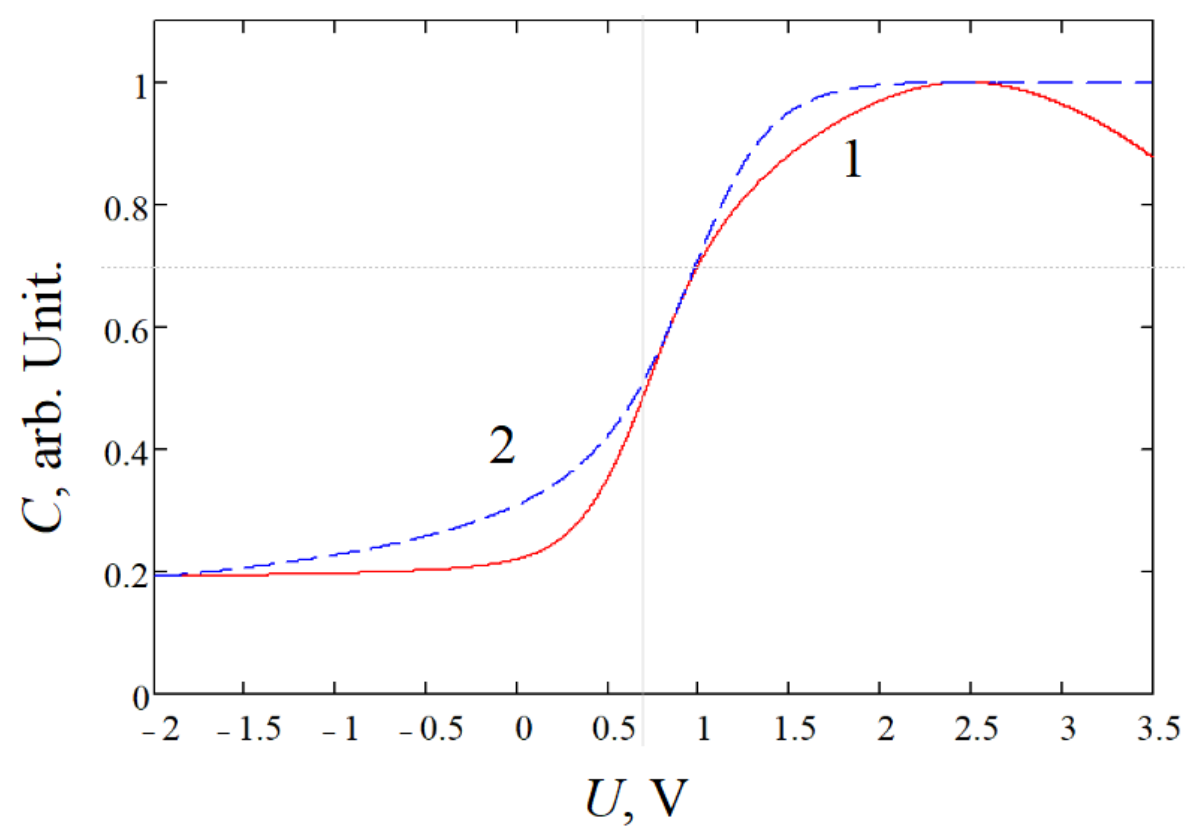

Fig. 4. Experimental $\mathrm{C}-\mathrm{V}$ characteristic for the sample of group 1 measured on Au contacts at a frequency of $1 \mathrm{kHz}$ (Trace 1) and modeled theoretical dependence for an ideal MIS structure at low frequencies with flat band voltage offset and the surface state density taken into account (Trace 2)

The use of the described method gives an acceptable agreement between the experimental and theoretical $\mathrm{C}-\mathrm{V}$ characteristics, which is confirmed by the value of the Pearson correlation coefficient $\mathrm{k}_{\mathrm{p}}=0.9959008$ (Pearson 1895). A similar approximation was carried out for all the samples when connected to rectifying $\mathrm{Au}$ ) and non-rectifying (In) contacts. Note that for all the samples, the model and experimental characteristics for the depletion region practically coincided.

Comparison of the measurement results was carried out for different contacts on each sample (Fig. 5).
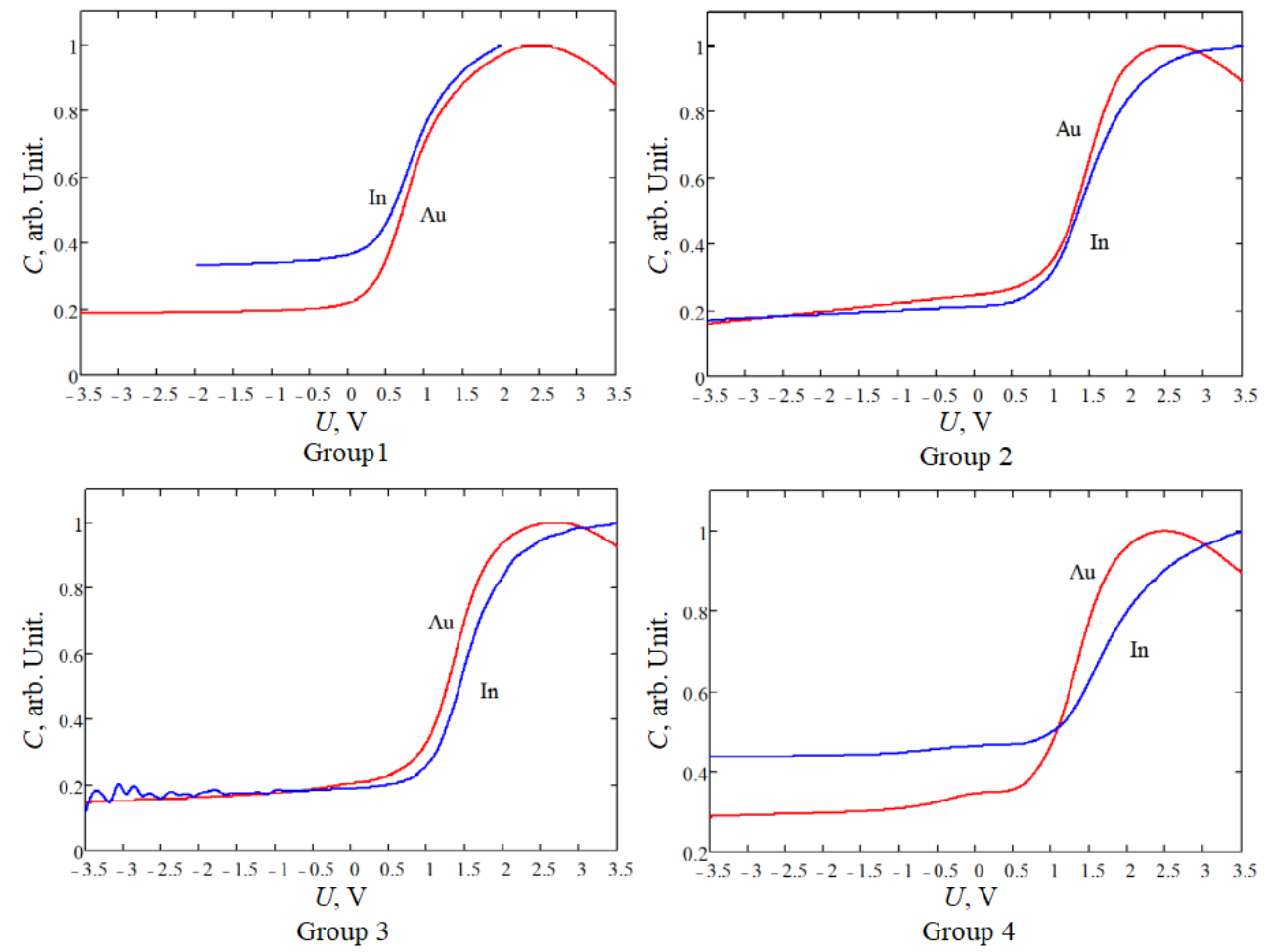

Fig. 5. Comparison of the normalized dependences of the effective capacity of the samples of a batch on the voltage for Au and In contacts 
The authors of (Pearton et al. 2005) noted the presence of electron traps with energies of 0.2 and 0.3 $\mathrm{eV}$ at the $\mathrm{Au}-\mathrm{ZnO}$ interface. Another factor affecting the capacitance characteristics is the possible inhomogeneity of the thickness of the $\mathrm{ZnO}$ thin film. The diffusion of metal atoms from the contacts into the bulk of $\mathrm{ZnO}$ is possible, which reduces the thickness of the insulating layer.

The comparison of the measurement results was carried out for different contacts on each sample. Since for each group of the samples we are talking about the same silicon substrate, the differential capacitance for each group of the samples should be the same. However, for the samples of groups 1 and 4, the differential capacities in the case of measurements at the $\mathrm{In} / \mathrm{ZnO} / \mathrm{n}-\mathrm{Si} / \mathrm{Al}$ and $\mathrm{Au} / \mathrm{ZnO} / \mathrm{n}-\mathrm{Si} /$ $\mathrm{Al}$ contacts are different. This may be due to the nonuniform distribution of defects and traps at the $\mathrm{ZnO} / \mathrm{n}$-Si interface, charge spreading, and an increase in the effective area of the upper contact when the $\mathrm{In} / \mathrm{ZnO} / \mathrm{n}-\mathrm{Si} / \mathrm{Al}$ contact is connected.

The difference between the theoretically calculated and experimental values of the specific capacity of the investigated samples with $\mathrm{Au} / \mathrm{ZnO} / \mathrm{n}-\mathrm{Si} / \mathrm{Al}$ contacts is shown in Fig. 6.

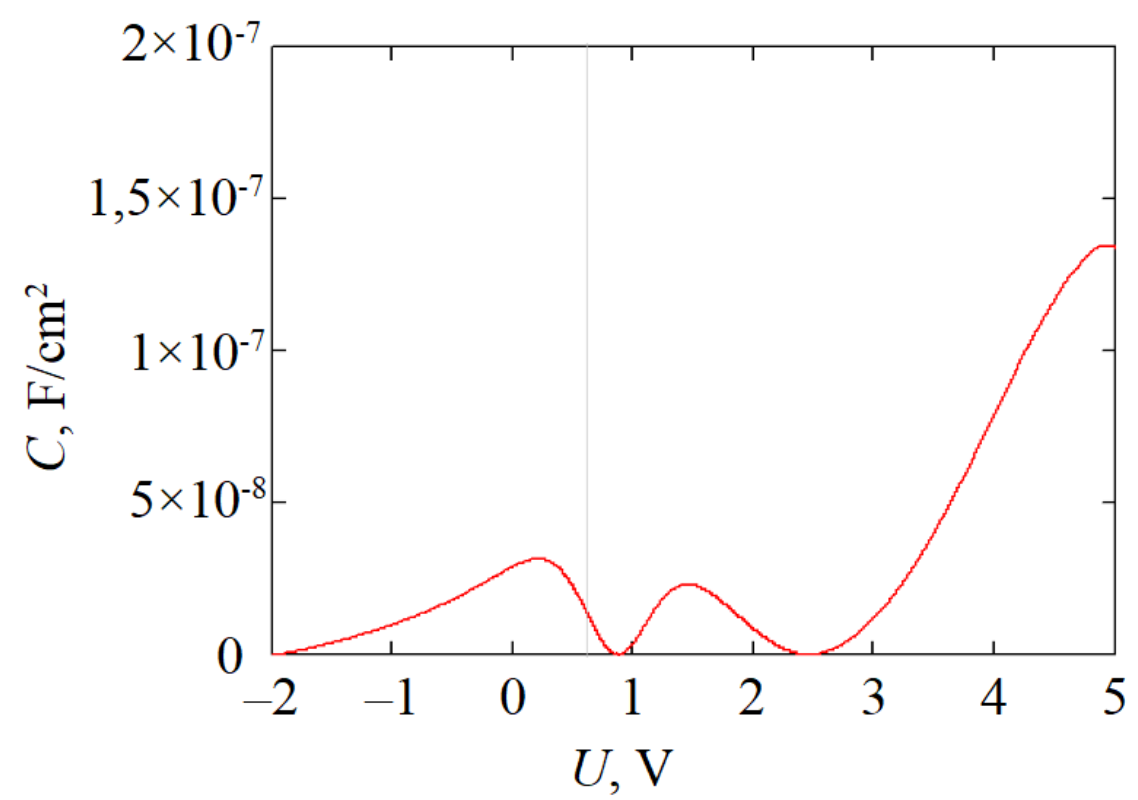

Fig. 6. The difference between the theoretically calculated and experimental value of the capacitance of the samples of batch 1 at the rectifying contacts at a frequency of $1 \mathrm{kHz}$

With an increase in the positive potential, a noticeable decrease in the $\mathrm{ZnO}$ capacitance is observed, possibly associated with the activation and movement of mobile ions in the dielectric film. The difference in the capacitance in the accumulation mode of the $\mathrm{In} / \mathrm{ZnO} / \mathrm{n}-\mathrm{Si} / \mathrm{Al}$ and $\mathrm{Au} / \mathrm{ZnO} / \mathrm{n}-\mathrm{Si} / \mathrm{Al}$ connections, and the type of capacitance-voltage characteristic for the rectifying contact indicated the presence of a built-in charge trapped in traps at the $\mathrm{Au}-\mathrm{ZnO}$ boundary.

\section{Conclusion}

The study of current-voltage and capacitance-voltage characteristics of semiconductor heterostructures $\mathrm{In} / \mathrm{ZnO} / \mathrm{n}-\mathrm{Si} / \mathrm{Al}$ and $\mathrm{Au} / \mathrm{ZnO} / \mathrm{n}-\mathrm{Si} / \mathrm{Al}$ has been carried out.

The influence of the technology of annealing the samples based on microcrystalline $\mathrm{ZnO}$ and the contact material on the characteristics of the structures is investigated.

It was found that the experimental capacitance-voltage characteristics of the objects under study are, in general, similar to the characteristics of MIS structures. Based on this, it was concluded that thin $\mathrm{ZnO}$ films in $\mathrm{In} / \mathrm{ZnO} / \mathrm{n}-\mathrm{Si} / \mathrm{Al}$ and $\mathrm{Au} / \mathrm{ZnO} / \mathrm{n}-\mathrm{Si} / \mathrm{Al}$ heterostructures can be regarded as an analogy of the dielectric of MIS structures.

The processing of the results obtained in the Mathcad programme made it possible to obtain the value of the density of surface states, the value of the built-in surface charge, to estimate the value of the concentration of free charge carriers in the silicon substrate, and other parameters. 
It was found that upon annealing zinc oxide films in argon, the effective density of states of $\mathrm{Au} / \mathrm{ZnO} / \mathrm{n}$-Si heterostructures is approximately an order of magnitude higher than upon annealing in oxygen $\left(3.5 \times 10^{12}\right.$ and $6 \times 10^{11} \mathrm{eV}^{-1} \mathrm{~cm}^{-2}$, respectively).

Possible reasons for the deviation of the capacitance of the heterostructure from the theoretically calculated values are analyzed.

\section{Conflict of Interest}

The authors declare that there is no conflict of interest, either existing or potential.

\section{Author Contributions}

A. R. Semenov and A. V. Ermachikhin carried out the planning and conducting of experimental research; V. G. Litvinov and T. A. Kholomina participated in the processing and interpretation of the results; all authors participated in the discussion of the results and the formulation of conclusions.

\section{Acknowledgements}

The authors are deeply grateful to D. G. Gromov and S. P. Oleinik (NRU MIET) for the samples provided for the study. The work was carried out using the equipment of the Regional Center for Probe Microscopy for Collective Use of the Ryazan State Radio Engineering University named after V. F. Utkin (RSREU).

\section{References}

Ellmer, K., Klein, A., Rech, B. (eds.). (2008) Transparent conductive zinc oxide. Basics and applications in thin film solar cells. Berlin; Heidelberg: Springer Verlag, 445 p. https://doi.org/10.1007/978-3-540-73612-7 (In English)

Gromov, D. G., Koz'min, A. M., Shulyat'ev, A. S. et al. (2013) Effect of the formation conditions on the properties of $\mathrm{ZnO}: \mathrm{Ga}$ thin films deposited by magnetron-assisted sputtering onto a cold substrate. Semiconductors, 47 (13), 1687-1691. https://doi.org/10.1134/S1063782613130083 (In English)

Kaidashev, E. M., Lorenz, M., von Wenckstern, H. et al. (2003) High electron mobility of epitaxial ZnO thin films on c-plane sapphire grown by multistep pulsed-laser deposition. Applied Physics Letters, 82 (22), 3901-3903. https://doi.org/10.1063/1.1578694 (In English)

Litvinov, V. G., Semenov, A. R., Kholomina, T. A. et al. (2018) Issledovanie spectra poverkhnostnykh sostoyanij na granitse razdela geterostruktury $\mathrm{ZnO} / \mathrm{Si}$ [Investigation of surface spectra on $\mathrm{ZnO} / \mathrm{Si}$ interface]. Vestnik Ryazanskogo gosudarstvennogo radiotekhnicheskogo universiteta - Vestnik of Ryazan State Radio Engineering University, 4 (66-2), 9-14. https://doi.org/10.21667/1995-4565-2018-66-4-2-9-14 (In Russian)

Muller, R. S., Chan, M., Kamins, T. I. (2003) Device electronics for integrated circuits. $3^{\text {rd }}$ ed. New York: Wiley Publ., 528 p. (In English)

Oreshkin, P. T. (1977) Fizika poluprovodnikov i dielektrikov [Physics of semiconductors and dielectrics]. Moscow: Vysshaya shkola Publ., 448 p. (In Russian).

Pearson, K. (1895) Note on regression and inheritance in the case of two parents. Proceedings of the Royal Society of London, 58 (347-352), 240-242. https://doi.org/10.1098/rspl.1895.0041 (In English)

Pearton, S. J., Norton, D. P., Ip, K. et al. (2005) Recent progress in processing and properties of ZnO. Progress in Materials Science, 50 (3), 293-340. https://doi.org/10.1016/j.pmatsci.2004.04.001 (In English)

Pintilie, L., Pintilie, I. (2001) Ferroelectrics: New wide-gap materials for UV detection. Materials Science and Engineering: B., 80 (1-3), 388-391. https://doi.org/10.1016/S0921-5107(00)00605-X (In English)

Semenov, A. R., Litvinov, V. G., Kholomina, T. A. et al. (2018) Investigating and modeling high frequency C-V characteristics of zinc oxide-based heterostructures. In: $7^{\text {th }}$ Mediterranean Conference on Embedded Computing: (MECO-2018). Budva: IEEE Publ., pp. 1-4. https://doi.org/10.1109/MECO.2018.8405999 (In English)

Sze, S. M. (1981) Physics of Semiconductor Devices. $2^{\text {nd }}$ ed. New York: Wiley Publ., 868 p. (In English) 